\title{
Teaching in Linguistically and Culturally Diverse Classrooms in Canada: Self-Efficacy Perceptions of Internationally Educated Teachers
}

Mithila Vidwans \& Farahnaz Faez

Set in Ontario, which is the most diverse province in Canada, this study ( $N=$ 76) examined Internationally Educated Teachers' (IETs) and non-Internationally Educated Teachers' (non-IETs) sense of self-efficacy for providing linguistically and culturally inclusive pedagogy in K-12 classrooms. Theories of self-efficacy and culturally responsive pedagogy frame this research. This study employed a quantitative 40-item survey to compare teachers' self-efficacy perceptions of general pedagogy and culturally responsive pedagogy. Results show that while both groups were equally consistent in their self-efficacy perceptions for providing general pedagogy, IETs reported significantly higher self-efficacy for providing culturally responsive pedagogy.

Réalisée en Ontario, la province la plus diversifiée du Canada, auprès d'enseignantes et enseignants formés à l'étranger (IETs) et d'enseignantes et enseignants formés ailleurs qu'à l'étranger (non-IETs), cette étude rend compte de la mesure dans laquelle ces professeurs se sentent personnellement capables d'offrir efficacement une pédagogie linguistiquement et culturellement inclusive dans les salles de classe de la maternelle à la douzième année. Éclairée par des recherches dans les domaines de l'auto-efficacité et de la pédagogie adaptée aux réalités culturelles, cette enquête quantitative basée sur la réponse à 40 questions a permis de comparer les perceptions d'auto-efficacité des enseignantes et enseignants à l'égard de la pédagogie en général et de la pédagogie adaptée aux réalités culturelles. Les résultats de l'enquête indiquent que, alors que les sentiments d'auto-efficacité des membres des deux groupes étaient uniformes quant à la pédagogie en général, les enseignantes et enseignants formés à l'étranger se sentent considérablement plus à même d'offrir une pédagogie adaptée aux réalités culturelles.

KEYWORDS: English Language Learners (ELLs), Internationally Educated Teachers (IETs), selfefficacy, linguistic and cultural diversity, culturally responsive pedagogy

Canadian classrooms are witnessing increasing linguistic and cultural diversity with more than half of the students speaking a first language (L1) other than English in a growing number of schools (Statistics Canada, 2017). Statistics Canada (2017) projects that by 2031, almost half of Canadians over the age of 15 will be foreign-born or will have a foreign-born parent. Previous studies 
have reported that in spite of the large number of English Language Learners (ELLs) ${ }^{1}$ in kindergarten through Grade 12 (K-12) classrooms in North America, teachers lack sufficient preparation to support these students (LadsonBillings, 2000; Rushton, 2000; Webster \& Valeo, 2011).

Equally important to note is that in spite of the increasing diversity in Canadian classrooms, the teaching profession has remained relatively homogeneous. More than two decades ago, Bascia (1996) expressed concerns that the "typical" teacher in Canada is a Canadian-born female who is of Caucasian race, belongs to the middle class, is heterosexual, able-bodied, and of Christian faith. More than two decades later, the situation remains unchanged (e.g., Janzen \& Cranston, 2016). In a 2016 report aimed at discussing challenges of implementing a diversity admissions policy at a Canadian university, Janzen and Cranston (2016) described that in spite of the increasing diversity in our communities, White female teachers make up more than $80 \%$ of the teaching force. Internationally Educated Teachers (IETs) ${ }^{2}$, defined by the Ontario College of Teachers (OCT) as teachers who have received their teaching certification in a country outside of Canada, have been reported to have higher unemployment and underemployment rates compared with other regulated professions for immigrants (Zietsma, 2010; Marom, 2017). Schmidt $(2010 b, 2016)$ contended that systemic discrimination is a major impediment to the integration of IETs in the teaching workforce. Discrimination of IETs has been reported in both teacher education programs (Cho, 2011; Schmidt \& Gagné, 2015) and in schools (Schmidt, 2010a). Yet, a range of arguments has been made in support of diversifying the Canadian teaching force (e.g., Villegas \& Lucas, 2002). Diversifying the teaching force is an important endeavour in realizing equitable representation (Ryan, Pollock, \& Antonelli, 2009), delivering relevant pedagogy (Solomon, 1997; Sleeter \& Milner, 2011), establishing relationships with students of diverse backgrounds (Villegas \& Lucas, 2004), and, eventually, better serving the needs of students from linguistically and culturally diverse backgrounds (Santoro, 2008).

Given the diversity in the student and teacher population in Canada, it is paramount to understand how teachers provide linguistically and culturally relevant pedagogy in their classrooms. One way to understand teachers' instructional ability is to examine their self-efficacy beliefs (Bandura, 1997). In layman's terms, self-efficacy is the confidence teachers have in their ability to perform specific tasks in the classroom. The study reported in this article is part of a larger study that looks at Ontario teachers' self-efficacy perceptions for teaching in diverse classrooms. Teachers in the larger study were grouped according to the grade level they taught, their linguistic background, as well as years of teaching experience. As a starting point, the purpose of this study was to explore the self-efficacy perceptions of IETs and non-IETs for teaching in culturally and linguistically diverse classrooms in the province of Ontario. Specifically, the study compared teachers' perceptions of self-efficacy for 
general pedagogy with their sense of self-efficacy for culturally responsive pedagogy.

\section{Theoretical Framework}

Theories of self-efficacy (Bandura, 1997) and culturally responsive pedagogy (Gay, 2000) frame this research. The concept of self-efficacy is based in Bandura's (1977) social cognitive theory and defined as the "beliefs in one's capabilities to organize and execute the courses of action required to manage prospective situations" (Bandura, 1995, p. 2). Simply put, skills and knowledge are insufficient to complete an action effectively, and one's confidence regarding their performance also has an impact on the success or failure of the action. Efficacy beliefs are important and have an impact on how individuals think, act, and feel. Not only do self-efficacy beliefs affect one's cognitive processes, but they are also linked to behaviour (Bandura, 1977). Efficacy beliefs "contribute significantly to human motivation and attainments" (Bandura, 1995, p. 3). Self-efficacy beliefs affect one's choice of activities and coping efforts in the face of obstacles. Bandura (1997) argued that the stronger one's self-efficacy perceptions, the more active the efforts. Teacher efficacy is an individual's judgement of their teaching ability (Bandura, 1977, 1997) and has significant educational implications (Tschannen-Moran \& Woolfolk Hoy, 2001). Teacher self-efficacy has been linked to notable educational outcomes such as student achievement (Akbari \& Allvar, 2010; Ashton \& Webb, 1986; Ross, 1992; Swanson, 2014), teacher attrition (Swanson, 2010, 2014), and teachers' sense of preparedness to teach in inclusive classrooms (Sharma, Loreman, \& Forlin, 2012). Therefore, teachers' self-efficacy beliefs have tremendous implications for understanding pedagogical outcomes, specific to this study, which involves teaching students from diverse backgrounds.

Canadian classrooms have witnessed students from culturally and linguistically diverse backgrounds for decades now. However, our classrooms, instructional methods, and the curricular content have been designed with those students who share the same homogeneous mainstream cultural environment in mind (Coelho, 2012). Consequently, students from culturally and linguistically diverse backgrounds who have experiences different from the mainstream students may be at a disadvantage. Coelho (2012) suggested that it is essential for teachers to understand that some students are learning the language of instruction and have knowledge that is drawn from other geographical regions of the world. Hence, it is paramount that pedagogical methods be relevant to culturally and linguistically diverse students so that they are given equal opportunities for success.

Culturally responsive pedagogy, in essence, addresses issues related to teaching in diverse classrooms, "using the cultural characteristics, experiences, and perspectives of ethnically diverse students as conduits 
for teaching them more effectively" (Gay, 2002, p. 106). Gay (2000) stated that when knowledge and skills are embedded within the lived experiences of students, their academic achievement improves. Five competencies of culturally responsive pedagogy are outlined. First, it is important that the knowledge base of a teacher goes beyond content knowledge and includes students' value systems, traditions, and learning styles. The second competency involves converting the acquired knowledge base into culturally responsive curricular designs and methods of instruction. Third, it is important to create classroom environments that are conducive to learning for students from diverse backgrounds. Fourth, teachers must acknowledge that styles of communication across cultures are different from the typical student-teacher dialogue in mainstream North American classrooms. The fifth competency involves the actual delivery of instruction in diverse classrooms in which teachers connect the prior knowledge of their students with new knowledge by building a bridge between what the students already know and what they will learn.

The theories of self-efficacy and culturally responsive pedagogy dovetail coherently in framing this study. ELLs' cultures and languages need to be validated in the curriculum and instruction for them to succeed (Gay, 2000). Self-efficacy perceptions of teachers have an impact on ELLs' academic success, and culturally responsive pedagogy is essential to ensuring that ELLs will succeed academically. As such, this study tries to specifically understand teachers' self-efficacy perceptions in relation to providing culturally responsive pedagogy. Hence, the two theories are compatible to the extent that they both strive to ensure the academic success of ELLs and have guided this study at every stage.

\section{Literature Review}

Multiple terms have been used throughout the literature to refer to IETs including "immigrant teachers," "overseas trained teachers," "foreign trained teachers," "foreign teachers," and "internationally trained teachers" (Walsh, Brigham, \& Wang, 2011). The OCT (2016) uses the term IET to refer to teachers with teacher education qualifications gained outside Ontario, and the term is used more broadly in this study to refer to a teacher who has studied, lived, or worked outside Canada for an extended period of time.

In addition to the call for a more diverse teaching force, researchers have also outlined the advantages of including IETs in the Canadian educational system, which benefits not only ELLs but all students. IETs help to interrupt the mainstream discourse that has existed for decades, in part, because of a homogeneous teaching force. In addition, other roles that IETs have undertaken in classrooms today include those of advocates and agents of change in ELL education (e.g., Beynon, Ilieva, \& Dichupa, 2004). They also show a great level of sensitivity and empathy toward ELLs (e.g., Faez, 2012a) and 
enrich the dialogue on immigrant integration (e.g., Phillion, 2003). IETs are also great cultural mediators and equity developers in the educational system (e.g., Block, 2012).

Despite the benefits of diversifying the teaching pool, IETs still face a number of issues, including discrimination in the workplace (e.g., Schmidt, 2010b), a devaluation of their diversity (e.g., Cho, 2011), and high rates of unemployment and underemployment (e.g., Deters, 2009). After extensive interviews with IETs and faculty members as well as classroom observations, Marom (2017) highlighted the structural barriers that stand in the way of the recertification process of IETs in British Columbia. Issues related to language including proficiency and accent are the biggest hindrance to employment. The IETs interviewed in the study point out how certain accents are accepted (e.g., British) but not others (e.g., Eastern European). The author also observed that "there was often an unspoken connection between language-especially accent-racism, and discrimination based on skin colour and ethnicity" (Marom, 2017, p. 171). In addition to language-related barriers, there were also structural barriers including the lack of sufficient information regarding the recertification process as well as the lack of recognition of teaching credentials from the IETs' home countries.

The prejudiced lens through which IETs' linguistic abilities are viewed is also evident in the literature. Broadly speaking, within the context of English as a second/foreign language (ESL/EFL), IETs belonging to expanding circle countries $^{3}$ (countries in which English has no official status, such as China and Iran) and sometimes even IETs from outer circle countries (countries previously colonized by Great Britain, such as India and Nigeria, in which English has an official status) are referred to as non-native English speaking teachers (NNESTs). Even though the native and non-native dichotomy is highly contested (e.g., Faez, 2011) and is shown to perpetuate racial and employment discrimination (e.g., Faez, 2012b; Kamhi-Stein, 2018; Selvi, 2018), these labels continue to be used, mainly for a lack of a better substitute term. Marom (2017) emphasizes that "this distinction between 'native' English speakers and 'others' reproduces linguistic hierarchies rather than promoting inclusivity and diversity" (p. 171). The potential strengths and shortcomings of NESTs and NNESTs are well documented in the literature (e.g., Moussu, 2018a, 2018b). Even though there are reports that some Internationally Educated Teacher Candidates (IETCs) may require support in their oral and written language skills (e.g., Faez, 2010), it is important to realize that there is a wide variation of expertise, language proficiency, and skills that IETs bring to the profession. Similar to non-IETs, there are vast within-group differences for IETs and the continued usage of the native/non-native dichotomy contributes even further to the discrimination and devaluation of IETs. Hence, it is important that teachers be evaluated based on their pedagogical skills rather than their native or non-native English speaker status. 


\section{Self-Efficacy for Providing General Pedagogy and Culturally Responsive Pedagogy}

In essence, the concept of self-efficacy suggests that skills and knowledge are not enough to complete an action effectively and that one's judgement regarding whether they will perform an act effectively also has an impact on it (Bandura, 1995). According to Bandura, self-efficacy beliefs influence individuals' thoughts, feelings, actions, behaviour, level of perseverance, as well as conflict-resolution techniques. Bandura (1995) states that "people's level of motivation, affective states, and actions are based more on what they believe than on what is objectively the case" (p. 2). In addition, self-efficacy beliefs of individuals differ depending on the context and the task. The stronger the teachers' self-efficacy perceptions, the stronger the efforts that they make in their teaching and in the goals they set for themselves (Woolfolk Hoy \& Spero, 2005). Also, many have pointed out that teachers' self-efficacy is positively correlated with student achievement and academic success (e.g., Bandura, 1995; Bolshakova, Johnson, \& Czerniak, 2011). Mojavezi and Tamiz (2012) looked at the relationship between teachers' self-efficacy and student motivation and achievement in Iran, and they reported that teachers with high levels of self-efficacy had a positive impact on student motivation.

Students belonging to diverse backgrounds do not always find the curriculum and instruction relevant to their experience (Siwatu, 2011b; Gay, 2000). As a result, it is essential that education be embedded within the lived experiences of the students so that all students have equal opportunities to gain academic success (Gay, 2000). Hence, it is important to examine teachers' perceptions about teaching practices that are generally beneficial to all students, defined as general pedagogy, as well as those that are specifically geared toward ELLs, referred to as culturally responsive pedagogy. Previous research on teachers' self-efficacy perceptions of providing culturally responsive pedagogy has been dependent on teachers' level of experience and the classroom context (e.g., Siwatu, 2011a). Research examining the relationship between self-efficacy and the linguistic background of the teachers specifically is sparse. This study attempts to fill a gap by examining the self-efficacy perceptions of Ontario teachers including IETs for teaching in diverse classrooms. In this investigation, teachers' self-efficacy was examined in relation to their general pedagogy, which entails implementing pedagogical practices geared toward all students, and also culturally responsive pedagogy, which are pedagogical practices geared toward all students but, particularly, toward ELLs. 


\section{Method}

This study explored the self-efficacy perceptions of Ontario's teachers to teach in diverse classrooms using a quantitative survey. The following research questions directed this study:

Research Question 1: What are the self-efficacy perceptions of Ontario's teachers regarding teaching in linguistically and culturally diverse classrooms? How do IETs' self-efficacy perceptions compare with non-IETs'?

Research Question 2: What are the self-efficacy perceptions of IETs and non-IETs on general and culturally responsive pedagogy practices?

Research Question 3: How do the self-efficacy perceptions of IETs compare with non-IETs on general and culturally responsive pedagogy practices?

\section{Participants}

The participants in this study comprised teachers across elementary, intermediate, and secondary (K-12) schools in Ontario. Data were collected by providing a letter of information to school boards to invite teachers to participate in the study. A background profile questionnaire, which included questions about participant's gender, age range, country of birth, K-12 education, university education, and dominant language, was distributed to the participants prior to the study. Of the 76 participants, 49 (64.5\%) were female, and $27(35.5 \%)$ were male. A total of $46(60.5 \%)$ were born, raised, and educated in Canada and also received their Bachelor of Education degree from a Canadian university. Five (6.6\%) were born in Canada and received most of their education in Canada but had also received some education including their teaching degree outside Canada, although they were at the time of the study qualified to teach in Canada. In total, 12 (15.8\%) were born elsewhere but came to Canada at a young age and received their education, including teacher certification, in Canada. Of the remaining 13 teachers, 10 (13.2\%) were born, raised, and educated outside Canada and had a Bachelor of Education degree from an institution outside Canada. However, regardless of which country had granted them their teaching degree, they had completed the teacher certification process in Ontario, which qualified them to teach in K-12 classrooms. Three (4\%) participants did not have a teaching certification from an international university but had completed the majority of their education prior to arriving in Canada. As a result of this variation in demographic data, two categories were identified, labelled as IETs $(n=13)$ and non-IETs $(n=63)$, from the total number of participants $(N=76)$. 


\section{The Survey Instrument}

The study reported in this article is part of a larger research project that employed mixed methods. The findings reported here are only based on the quantitative data. The survey instrument used in this research is based on Siwatu's (2007) Culturally Responsive Teaching Self-Efficacy (CRTSE) scale. The survey seeks to measure the participants' perceptions of self-efficacy on a series of 40 items dealing with pedagogical practices in diverse classrooms. Teachers were asked to rate how they judged their capabilities (perceived self-efficacy) on the 40 teaching practices on a scale of 0 (no feelings of selfefficacy) to 10 (high feelings of self-efficacy). The survey items were tailored to suit the teaching and learning context in Ontario schools and the goals of this study. No changes were made to 25 items, and they remained as they were in the original survey. Two items were combined into one. Six items were deleted because they either did not address the goals of the study directly or were redundant. Contextual details were added to eight items to make them fit the Ontario context. Six items dealing with linguistically relevant pedagogy were added based on previous research looking at the role of language in subject-specific domains such as science and mathematics. However, even after the changes were made, the survey remained at 40 items in length. The final version of the survey is shown in the appendix.

Siwatu (2007) reported the validation procedures and internal consistency reliability of the survey. The changes that were made to the survey, in turn, may have changed the internal consistency reliability of the original version of the survey. Hence, it was essential to ensure that the adapted version of the survey was also reliable. To examine the correlation between all of the variables, Cronbach's alpha was implemented. Muijs (2011) stated that a high Cronbach's alpha indicates high levels of internal consistency and suggested that a measure above .7 was considered acceptable for research purposes. The internal reliability for the original CRTSE survey was .96 (Siwatu, 2007). After making appropriate modifications to the original survey, the Cronbach's alpha of the adapted survey was still high at .95-thus, establishing a strong internal consistency reliability of the instrument.

\section{Data Analysis Procedures}

Siwatu's (2007) CRTSE survey was chosen because of its variation in survey items dealing with general pedagogy as well as culturally responsive pedagogy. Culturally responsive pedagogy takes ELLs' cultural and linguistic backgrounds into account in terms of the curriculum, instruction, and teaching practices while general pedagogy involves teaching practices that are considered to be effective for all students, regardless of their cultural and linguistic backgrounds. Based on these definitions, we classified the survey items into two categories: general or culturally responsive. In addition to the authors, two doctoral students and one faculty member also categorized the 
survey items to check the level of agreement between our categorization. There was agreement on all but two of the survey items (items 11 and 14) among the coders compared with our individual categorization. After a discussion, all agreed that item 14 was culturally responsive, and item 11 was general pedagogy. After establishing an agreement on all of the survey items, the final categorization included 18 items belonging to the general pedagogy category and 22 to the culturally responsive pedagogy category.

First, we calculated the means and standard deviations of the teachers' scores on the 40 items of the survey. We calculated the overall means and standard deviations for each of the participants. We also calculated the overall self-efficacy of IETs and non-IETs as a collective to compare the groups through independent samples $t$ tests. Second, we conducted an additional $t$ test to see if there were statistically significant differences between general pedagogical practices and culturally responsive pedagogical practices. The results from our analysis are presented in the next section.

\section{Findings}

The findings from the survey data are presented corresponding to the three research questions: First, we report on findings related to the overall selfefficacy perceptions of the participant teachers and provide a comparison between IETs' and non-IETs' overall self-efficacy perceptions to teach in diverse classrooms in Ontario. Second, we provide a comparison of both groups' (IETs' and non-IETs') self-efficacy perceptions on items of general as opposed to culturally responsive pedagogy. Third, we present a comparison between IETs' and non-IETs' overall self-efficacy perceptions on items of general pedagogy and culturally responsive pedagogy. In keeping with Siwatu's (2007) survey, we have kept the original 0-10 scale for this adapted survey as well.

The first research question dealt with the overall self-efficacy perceptions of Ontario's teachers regarding teaching in linguistically and culturally diverse classrooms and a comparison between IETs' and non-IETs' selfefficacy.

\section{Overall Self-Efficacy and Comparison of IETs versus Non-IETs}

Of the total number of participants $(N=76), 13$ were IETs and 63 were NonIETs. The overall mean (for all participants on the entire survey) was 7.20 $(S D=1.07)$. The overall mean of the IETs $(n=13)$ was $7.80(S D=0.76)$ and Non-IETs $(n=63)$ was $7.08(S D=1.30)$. Levene's test for unequal variances was conducted, and it showed that the variances were not significantly different, $F(74)=3.785, p=.056$. The results of the $t$ test, $t(74)=1.921, p=.056$, showed that there were no statistically significant differences between the subgroups. Hence, there were no statistically significant differences between 
IETs' and non-IETs' overall self-efficacy perceptions for teaching in linguistically and culturally diverse classrooms.

Table 1

Descriptive Statistics of IETs' and Non-IETs' Self-Efficacy on the Overall Survey

\begin{tabular}{lllll}
\hline IET or Non-IET & $N$ & $M$ & $S D$ & Std. Error $M$ \\
\hline IET & 13 & 7.80 & 0.76 & 0.21 \\
Non-IET & 63 & 7.08 & 1.30 & 0.16 \\
\hline
\end{tabular}

Note. IET = Internationally Educated Teachers; non-IET = non-Internationally Educated Teachers.

The second research question dealt with the self-efficacy perceptions of IETs and non-IETs on general and culturally responsive pedagogy items.

IETs: General Pedagogy versus Culturally Responsive Pedagogy

Of the total number of participants $(N=76)$, the number of IETs was 13 . Their overall mean on general pedagogy items (18), which include teaching practices that are considered to be effective for all students, regardless of their cultural and linguistic backgrounds, was $8.25(S D=0.45)$ and on culturally responsive pedagogy items (22), which are those that take ELLs' cultural and linguistic backgrounds into account in terms of the curriculum, instruction, and teaching practices, was $7.43(S D=0.65)$. Levene's test for unequal variances found that the variances were not significantly different, $F(38)=3.142$, $p=.084$. The result of the $t$ test showed that there is a statistically significant difference between the IETs' self-efficacy perceptions on items of general pedagogy as opposed to culturally responsive pedagogy, $t(38)=4.555, p=0$. IETs reported higher confidence in their ability to implement general pedagogy as opposed to culturally responsive pedagogy.

Table 2

IETs' Self-Efficacy on General Pedagogy (GP) and Culturally Responsive Pedagogy (CRP) Items

\begin{tabular}{lllll}
\hline GP or CRP & $N$ & $M$ & $S D$ & Std. Error $M$ \\
\hline GP & 18 & 8.25 & 0.45 & 0.11 \\
CRP & 22 & 7.43 & 0.65 & 0.14 \\
\hline
\end{tabular}

Note. IET = Internationally Educated Teachers.

Non-IETs: General Pedagogy versus Culturally Responsive Pedagogy Of the total number of participants $(N=76)$, the number of non-IETs was 63 . Their overall mean on general pedagogy items $(18)$ was $8.03(S D=0.63)$ and on culturally responsive pedagogy items was $6.30(S D=0.89)$. Levene's test for unequal variances found that the variances were not significantly different, $F(38)=1.532, p=.223$. The result of the $t$ test showed that there is a statis- 
tically significant difference between the non-IETs' self-efficacy perceptions on items of general pedagogy as opposed to culturally responsive pedagogy, $t(38)=6.886, p=0$. Non-IETs also reported higher confidence in their ability to implement general pedagogy as opposed to culturally responsive pedagogy.

Table 3

Non-IETs' Self-Efficacy on General Pedagogy (GP) and Culturally Responsive Pedagogy (CRP) Items

\begin{tabular}{lllll}
\hline GP or CRP & $N$ & $M$ & $S D$ & Std. Error $M$ \\
\hline GP & 18 & 8.03 & 0.63 & 0.15 \\
CRP & 22 & 6.30 & 0.89 & 0.19 \\
\hline
\end{tabular}

Note. Non-IET = non-Internationally Educated Teachers.

The third research question dealt with a comparison of self-efficacy perceptions of the IETs and the non-IETs on general and culturally responsive pedagogy items.

\section{IETs versus Non-IETs: General Pedagogy}

Of the 40 items on the survey, there were 18 general pedagogy items. The overall mean of the IETs $(n=13)$ on general pedagogy items (18) was 8.25 $(S D=0.85)$ and Non-IETs $(n=63)$ was $8.03(S D=1.05)$. Levene's test for unequal variances showed that the variances were not significantly different, $F(74)=0.269, p=.606$. The results of the $t$ test, $t(74)=0.718, p=.475$, showed that there were no statistically significant differences between the subgroups. Hence, IETs and non-IETs reported no statistically significant differences in their confidence to implement general pedagogy in the classroom.

Table 4

IETs versus Non-IETs' Self-Efficacy on General Pedagogy (GP) Items

\begin{tabular}{lllll}
\hline IET or Non-IET & $N$ & $M$ & $S D$ & Std. Error $M$ \\
\hline IET & 13 & 8.25 & 0.85 & 0.24 \\
Non-IET & 63 & 8.03 & 1.05 & 0.13 \\
\hline
\end{tabular}

Note. IET = Internationally Educated Teachers; non-IET = non-Internationally Educated Teachers.

IETs versus Non-IETs: Culturally Responsive Pedagogy

Of the 40 items on the survey, there were 22 culturally responsive pedagogy items. The overall mean of the IETs $(n=13)$ on culturally responsive pedagogy items $(22)$ was $7.43(S D=0.81)$ and the non-IETs $(n=63)$ was $6.30(S D=$ 1.70). Levene's test for unequal variances found that the variances were significantly different, $F(74)=9.334, p=.003$. The result of the $t$ test showed that there is a statistically significant difference between IETs and non-IETs' selfefficacy perceptions on items of culturally responsive pedagogy, $t(74)=3.622$, 
$p=.001$. Hence, compared with non-IETs, IETs reported higher confidence in their ability to implement culturally responsive pedagogy.

Table 5

IETs versus Non-IETs' Self-Efficacy on Culturally Responsive Pedagogy (CRP) Items

\begin{tabular}{lllll}
\hline IET or Non-IET & $N$ & $M$ & $S D$ & Std. Error $M$ \\
\hline IET & 13 & 7.43 & 0.81 & 0.22 \\
Non-IET & 63 & 6.30 & 1.70 & 0.21 \\
\hline
\end{tabular}

Note. IET = Internationally Educated Teachers; non-IET = non-Internationally Educated Teachers.

\section{Discussion}

We discuss the findings based on the three research questions posed earlier. Both IETs and non-IETs reported a high self-efficacy in their overall ability to teach in diverse classrooms $(M=7.20 ; S D=1.07)$. Findings show that there are no statistically significant differences between the two groups in terms of their overall self-efficacy. The three highest rated survey items were item 10, which read "I use a variety of teaching methods such as visual aids"; item 8 , which read "I build a sense of trust in my students"; and item 28, which read "I help students feel like important members of the classroom." In contrast, the lowest rated items were item 18 , which read "I design my classroom environment using displays that reflect a variety of cultures"; item 16, which read "I teach students about their cultures' contributions to fields such as science if content and context permit"; and item 17, which read "I greet ELLs with a phrase in their L1 if I am able to." Siwatu (2007) mentioned the importance of item-specific responses in addition to the overall global score on self-efficacy measures. In fact, he posits that global self-efficacy scores mask the particular areas in which participants have low efficacy, which need to be targeted by appropriate stakeholders such as teacher education programs or school boards. These findings clearly point out that teachers have low self-efficacy on pedagogical practices that are directly related to teaching culturally and linguistically diverse students. The highest rated survey items are more general in nature and do not quite deal with issues of diversity directly. These findings are in alignment with previous research that shows that culturally responsive pedagogy has been discussed extensively within research communities, but the practical aspect of the theory does not effectively reach the practitioners (Boutte, Kelly-Jackson, \& Johnson, 2010). Hence, teachers' low self-efficacy on these items shows that they may be unsure of how to enact these practices in the classroom.

When looking closer at differences between teachers' perception of their efficacy for general pedagogy and culturally responsive pedagogy, both IETs and non-IETs report higher confidence in their ability to implement general pedagogy as opposed to culturally responsive pedagogy. The statistically significant difference between teaching practices of general pedagogy and 
culturally responsive pedagogy in this study supports the theoretical understanding concerning the nature of self-efficacy beliefs, which indicates that general beliefs of self-efficacy do not generate self-efficacy beliefs in specific tasks (Bandura, 1997). Teachers had a significantly higher sense of efficacy on general pedagogical practices compared with culturally responsive pedagogical practices. This finding is not surprising given that previous studies have reported that well-intentioned teachers lack the expertise to address the needs of ELLs in multilingual classrooms in Ontario (Webster \& Valeo, 2011).

Knoblauch and Hoy (2008) have stated that teachers' self-efficacy has a fundamental influence on pedagogical practices. Teachers in this study are more likely to enact the general pedagogical practices for which they felt highly efficacious rather than the culturally responsive practices regardless of the proportion of ELLs in their classrooms. Bandura (1997) stated that not only are individuals likely to enact their beliefs when they feel highly selfefficacious about them but they will put forth a more active effort in those activities. Hence, it is possible that as a result of their relatively low efficacy on pedagogical practices dealing directly with diversity (compared with general pedagogy), teachers do not generally adopt culturally responsive teaching practices in their classrooms. Even if they do, they may not expend a large amount of effort in incorporating more inclusive teaching practices in the classroom. In their study of six kindergarten teachers' perceptions regarding providing culturally responsive education in their classrooms, Alaca and Pyle (2018) found that while mostly all teachers believed in affirming their students' backgrounds in their teaching, only a few reported implementing specific practices regularly in their teaching. This is also true in the case of other participants. In her study examining interactions between secondary ELLs engaged in math peer tutoring sessions, Cardimona (2018) states that most teachers of mathematics have minimal or no training for working with ELLs.

These findings are also in accordance with previous research showing a lack of preparedness on the part of the teachers to teach in culturally and linguistically diverse classrooms (e.g., Lucas, Villegas, \& Martin, 2015). Proponents of culturally responsive pedagogy including Gay (2000) have stated that general pedagogy serves the needs of mainstream students and culturally responsive pedagogy serves the needs of ELLs. Coelho (personal communication, author 2, 2005) argues that instruction geared to suit the needs of ELLs is simply "good pedagogy." Evidently, these findings reiterate that curriculum, instruction, and pedagogy are largely geared toward students who belong to the mainstream culture of the society (Gay, 2000; Coelho, 2012). Mensah (2011) pointed out that for students to learn in culturally relevant ways, it is important that their teachers first learn and understand the principles of culturally responsive pedagogy themselves so that they can teach appropriately. Culturally responsive pedagogy advocates have mentioned that student failure is attached to the teacher (Collier, 2005). This helps us 
understand that if ELLs belonging to diverse cultural and linguistic groups are underperforming, one possible way to help them succeed in their academic work would be to provide them with appropriate culturally and linguistically responsive pedagogy.

Finally, while IETs and non-IETs report no significant difference in their ability to implement general pedagogy, IETs report higher confidence in their ability to implement culturally responsive pedagogy. Considering that the knowledge of additional languages other than English was a prevalent factor among IETs in this study and that culturally responsive teaching practices take ELLs' languages into account, the results are in alignment with previous research. A study by Coady, Harper, \& De Jong (2011) stressed that certain background characteristics can have an impact on teacher preparedness in terms of teaching ELLs and found that "LOTE [language(s) other than English] proficiency" was a particularly significant variable that had a positive correlation with teacher preparedness for teaching ELLs. In their study, García-Nevarez, Stafford, and Arias (2005) also found that Spanishspeaking Latino teachers had more positive attitudes toward using ELLs' L1 in the classroom than non-Latino teachers who did not speak Spanish. It is also possible that IETs reported higher self-efficacy as a result of the empathy and understanding that they may feel for ELLs due to similar background experiences even though higher empathy does not necessarily translate into appropriate pedagogical practices (Faez, 2012a). Whatever the reason, IETs reported higher self-efficacy for providing culturally responsive pedagogy in this study and, hence, the current study supports calls for diversifying the teaching force.

\section{Conclusion}

Regardless of our sincere effort to conduct this investigation and examine the self-efficacy perceptions of IETs in relation to non-IETs, there are a number of limitations of this study. First, this study relied on self-perceptions of self-efficacy of IETs and non-IETs, and self-reports can be viewed to be unreliable (Trofimovich Isaacs, Kennedy, Saito, \& Crowther, 2016) in spite of Bandura's (1995) emphasis on the significance of one's confidence in their ability. Second, the number of non-IETs is much larger than the number of IETs in this study. This small sample size reflects the small number of IETs employed in the teaching profession, and our difficulty in recruiting a larger number of IETs did not come as a surprise due to the small pool of practicing IETs in the profession. Consequently, the results of this study must be comprehended with this in mind. Third, the definition used to identify IETs can be viewed as subjective, and there is a wide within-group variation in both IETs and nonIETs. Hence, any grouping can be perceived to be problematic because these variations cannot be captured in such groupings and labelling. However, it is important to see how IETs perform as a group because they are consistently 
labelled in social contexts, and their contributions are undermined. It is also important to bear in mind that the IETs in this study were practicing teachers with secure employment and, hence, may be different from IETs in preservice programs (e.g., Faez, 2010, 2012a).

Regardless of the limitations, results from this study highlight a number of important findings. Both IETs and non-IETs report an overall high selfefficacy to teach in diverse classrooms. No statistically significant differences were found between the two groups. Both groups reported a much higher self-efficacy on items of general pedagogy as opposed to culturally responsive pedagogy with statistically significant differences. In addition, while no statistically significant differences were found between both groups on general pedagogy, IETs reported a significantly higher self-efficacy on culturally responsive items than non-IETs. Given the findings of this study, school boards should be more open and welcoming toward recruiting IETs as they not only diversify the teaching force and address issues related to better student representation but also reported a stronger self-efficacy for providing culturally responsive pedagogy than non-IETs in this study. While the findings reported in this investigation were based on a study conducted in Ontario, the issues can be similar in other linguistically and culturally diverse contexts.

\section{Notes}

1. The Ontario Ministry of Education (2007) uses the term English Language Learner (ELL) to refer to students whose first language is not English or is a variety of English significantly different from the variety used in Ontario classrooms. ELLs may be born in Canada or may have arrived from other countries.

2. According to the Ontario College of Teachers, Internationally Educated Teachers (IETs) are those "who have completed a teacher education program outside of Ontario" (Ontario College of Teachers, 2016, p. 2). We define IETs more broadly to include teachers who have studied for an extended period of time outside Canada.

3. Kachru (1992) developed the three-circle model of World Englishes, which remains a widely used framework for grouping the different varieties of English throughout the world.

\section{The Authors}

Mithila Vidwans, PhD, completed her graduate education from Western University. Her research interests include corpus linguistics and teacher education.

Farahnaz Faez, PhD, is an associate professor in the Faculty of Education at the University of Western Ontario, Canada. She has taught and supervised ESL/EFL and TESOL programs for several years. Her research interests include second/foreign language pedagogy and language teacher education with a focus on teacher efficacy, teacher cognition, teacher proficiency, and non-native English speaking teachers. 


\section{References}

Akbari, R., \& Allvar, N. K. (2010). L2 Teacher characteristics as predictors of students' academic achievement. The Electronic Journal for English as a Second Language, 13(4), 1-22.

Alaca, B., \& Pyle, A. (2018). Kindergarten teachers' perspectives on culturally responsive education. Canadian Journal of Education, 41(3), 753-782.

Ashton, P. T., \& Webb, R. B. (1986). Making a difference: Teachers' sense of efficacy and student achievement. White Plains, NY: Longman.

Bandura, A. (1977). Self-efficacy: Toward a unifying theory of behavioral change. Psychological Review, 84(2), 191-215. http://dx.doi.org/10.1037/0033-295X.84.2.191

Bandura, A. (1995). Exercise of personal and collective efficacy in changing societies. In A. Bandura (Ed.), Self-efficacy in changing societies (pp. 1-45). Cambridge: Cambridge University Press. http://dx.doi.org/10.1017/CBO9780511527692.003

Bandura, A. (1997). Self-efficacy: The exercise of control. New York, NY: W. H. Freeman and Company.

Bascia, N. (1996). Teacher leadership: Contending with adversity. Canadian Journal of Education, 21(2), 155-169.

Beynon, J., Ilieva, R., \& Dichupa, M. (2004). Re-credentialling experiences of immigrant teachers: Negotiating institutional structures, professional identities and pedagogy. Teachers and Teaching, 10(4), 429-444. https://doi.org/10.1080/1354060042000224160

Block, L. A. (2012). Re-positioning: Internationally educated teachers in Manitoba school communities. Canadian Journal of Education, 35(3), 85-100.

Bolshakova, V. L. J., Johnson, C. C., \& Czerniak, C. M. (2011). “It depends on what science teacher you got": Urban science self-efficacy from teacher and student voices. Cultural Studies of Science Education, 6(4), 961-997.

Boutte, G., Kelly-Jackson, C., \& Johnson, G. L. (2010). Culturally relevant teaching in science classrooms: Addressing academic achievement, cultural competence, and critical consciousness. International Journal of Multicultural Education, 12(2), 1-20. http://dx.doi.org/10.18251/ ijme.v12i2.343

Cardimona, K. (2018). Differentiating mathematics instruction for secondary-level English language learners in the mainstream classroom. TESOL Journal, 9(1), 17-57. https://doi. org/10.1002/tesj.303

Cho, C. L. (2011). Qualifying as a teacher: Investigating immigrant teacher candidates' counter stories of replication and resistance (Doctoral dissertation). Retrieved from ProQuest Dissertations and Theses database. (NR80550)

Coady, M., Harper, C., \& De Jong, E. (2011). From preservice to practice: Mainstream elementary teacher beliefs of preparation and efficacy with ELLs in the state of Florida. Bilingual Research Journal, 34(2), 223-239. https://doi.org/10.1080/15235882.2011.597823

Coelho, E. (2012). Language and learning in multilingual classrooms: A practical approach. Bristol: Multilingual Matters.

Collier, M. D. (2005). An ethic of caring: The fuel for high teacher efficacy. The Urban Review, $37(4), 351-358$.

Deters, P. K. (2009). Identity, agency, and the acquisition of professional language and culture: The case of internationally educated teachers and college professors in Ontario. (Doctoral dissertation). Retrieved from ProQuest Dissertations and Theses database.

Faez, F. (2010). Linguistic and cultural adaptation of internationally educated teacher candidates. Canadian Journal for Educational Administration and Policy [Special Issue], 100, 1-20.

Faez, F. (2011). Reconceptualizing the native/nonnative speaker dichotomy. Journal of Language, Identity and Education, 10(4), 231-249.

Faez, F. (2012a). Diverse teachers for diverse students: Internationally educated and Canadianborn teachers' preparedness to teach English language learners. Canadian Journal of Education, 35(3), 64-84. 
Faez, F. (2012b). Linguistic identities and experiences of generation 1.5 teachers: Race matters. TESL Canada Journal, 29(6), 124-141.

Fehr, M. C. (2010). Unlikely teachers: Redefining the best and the brightest. Multicultural Education \& Technology Journal, 4(4), 272-281.

García-Nevarez, A. G., Stafford, M. E., \& Arias, B. (2005). Arizona elementary teachers' attitudes toward English language learners and the use of Spanish in classroom instruction. Bilingual Research Journal, 29(2), 295-317. https://doi.org/10.1080/15235882.2005.10162837

Gay, G. (2000). Culturally responsive teaching: Theory, research, E practice. New York, NY: Teachers College Press.

Gay, G. (2002). Preparing for culturally responsive teaching. Journal of Teacher Education, 53(2), 106-116. https://doi.org/10.1177/0022487102053002003

Gay, G. (2015). Teachers' beliefs about cultural diversity: Problems and possibilities. In H. Fives \& M. G. Gill (Eds.), International handbook of research on teachers' beliefs (pp. 436-452). New York, NY: Routledge.

Janzen, M., \& Cranston, J. (2016). The challenges of implementing a diversity admission policy. University Affairs. Retrieved from http://www.universityaffairs.ca/opinion/in-my-opinion/ challenges-implementing-diversity-admissions-policy/

Kachru, B. B. (1992). World Englishes: Approaches, issues and resources. Language Teaching, 25, 1-14.

Kamhi-Stein, L. D. (2018). Challenges faced by NNESTs. In John I. Liontas (Ed.), The TESOL encyclopedia of English Language Teaching (Vol. 2, pp. 1-7). Hoboken, New Jersey: John Wiley \& Sons, Inc. DOI: 10.1002/9781118784235.eelt0010

Knoblauch, D., \& Hoy, W. A. (2008). "Maybe I can teach those kids": The influence of contextual factors on student teachers' efficacy beliefs. Teaching and Teacher Education, 24(1), 166-179.

Ladson-Billings, G. (2000). Fighting for our lives: Preparing teachers to teach African American students. Journal of Teacher Education, 51(3), 206-214. https://doi. org/10.1177/0022487100051003008

Levin, B. B. (2015). The development of teachers' beliefs. In H. Fives \& M. G. Gill (Eds.), International handbook of research on teachers' beliefs (pp. 48-65). New York, NY: Routledge.

Lucas, T., Villegas, A. M., \& Martin, A. D. (2015). Teachers' beliefs about English language learners. In H. Fives \& M. G. Gill (Eds.), International handbook of research on teachers' beliefs (pp. 453-474). New York, NY: Routledge.

Marom, L. (2017). Mapping the field: Examining the recertification of internationally educated teachers. Canadian Journal of Education, 40(3), 157-190.

Mensah, F. M. (2011). A case for culturally relevant teaching in science education and lessons learned for teacher education. The Journal of Negro Education, 80(3), 296-309.

Moussu, L. (2018a). Shortcomings of NESTs and NNESTs. In John I. Liontas (Ed.), The TESOL encyclopedia of English Language Teaching (Vol. 2, pp. 1-6). Hoboken, New Jersey: John Wiley \& Sons, Inc. DOI: 10.1002/9781118784235.eelt0044

Moussu, L. (2018b). Strengths of NESTs and NNESTs. In John I. Liontas (Ed.), The TESOL encyclopedia of English Language Teaching (Vol. 2, pp. 1-7). Hoboken, New Jersey: John Wiley \& Sons, Inc. DOI: 10.1002/9781118784235.eelt0813

Mojavezi, A., \& Tamiz, M. P. (2012). The impact of teacher self-efficacy on the students' motivation and achievement. Theory and Practice in Language Studies, 2(3), 483-491. https://doi. org/10.29333/ejmste/89579

Muijs, D. (2011). Doing quantitative research in education with SPSS (2nd ed.). Thousand Oaks, CA: Sage.

Ontario College of Teachers. (2016). Career map for internationally educated teachers. Toronto, Ontario: Queen's Printer for Ontario.

Ontario Ministry of Education. (2007). English language learners: ESL and ELD programs and service: Policies and procedures for Ontario elementary and secondary schools, Kindergarten to Grade 12. Toronto, Canada: Ontario Ministry of Education. 
Phillion, J. (2003). Obstacles to accessing the teaching profession for immigrant women. Multicultural Education, 11(1), 41-45.

Ross, J. A. (1992). Teacher efficacy and the effect of coaching on student achievement. Canadian Journal of Education, 17(1), 51-65. http://dx.doi.org/10.2307/1495395

Rushton, S. P. (2000). Student teacher efficacy in inner-city schools. The Urban Review, 32(4), 365-383. https://doi.org/10.1023/A:1026459809392

Ryan, J., Pollock, K., \& Antonelli, F. (2009). Teacher diversity in Canada: Leaky pipelines, bottlenecks, and glass ceilings. Canadian Journal of Education, 32(3), 591-617.

Santoro, N. (2008). "Outsiders" and "others": "Different" teachers teaching in culturally diverse classrooms. Teachers and Teaching, 13(1), 81-97. https://doi.org/10.1080/13540600601106104

Selvi, A. F. (2018). Myths and misconceptions about the NNEST movement and research. In John I. Liontas (Ed.), The TESOL encyclopedia of English Language Teaching (Vol. 2, pp. 1-8). Hoboken, New Jersey: John Wiley \& Sons, Inc. DOI: 10.1002/9781118784235.eelt0811

Schmidt, C. (2010a). Introduction: Moving from the personal to the political in IET scholarship. Canadian Journal of Educational Administration and Policy, 100, 1-4. Retrieved from https:// journalhosting.ucalgary.ca/index.php/cjeap/issue/view/2882

Schmidt, C. (2010b). Systemic discrimination as a barrier for immigrant teachers. Diaspora, Indigenous, and Minority Education, 4(4), 235-252. https://doi.org/10.1080/15595692.2010.513 246

Schmidt, C. (2016). Herculean efforts are not enough: Diversifying the teaching profession and the need for systemic change. Intercultural Education, 26(6), 584-592. https://doi.org/10.1080/ 14675986.2015.1109776

Schmidt, C., \& Gagné, A. (2015). Internationally educated teacher candidates in Canadian faculties of education: When diversity $\neq$ equity. In T. Falkenberg (Ed.), Handbook of Canadian research in initial teacher education (pp. 295-311). Ottawa, ON: Canadian Association for Teacher Education.

Sharma, U., Loreman, T., \& Forlin, C. (2012). Measuring teacher efficacy to implement inclusive practices. Journal of Research in Special Educational Needs, 12(1), 12-21. https://doi.org/10.1111/ j.1471-3802.2011.01200.x

Siwatu, K. O. (2007). Preservice teachers' culturally responsive teaching self-efficacy and outcome expectancy beliefs. Teaching and Teacher Education, 23(7), 1086-1101. https://doi.org /10.1080/00220671.2010.487081

Siwatu, K. O. (2011a). Preservice teachers' sense of preparedness and self-efficacy to teach in America's urban and suburban schools: Does context matter? Teaching and Teacher Education, 27(2), 357-365. https://doi.org/10.1016/j.tate.2010.09.004

Siwatu, K. O. (2011b). Preservice teachers' culturally responsive teaching self-efficacy-forming experiences: A mixed-methods study. The Journal of Educational Research, 104(5), 360-369. https://doi.org/10.1080/00220671.2010.4870

Sleeter, C. E., \& Milner, H. R. (2011). Researching successful efforts in teacher education to diversify teachers. In A. F. Ball \& C. A. Tyson (Eds.), Studying diversity in teacher education (pp. 81-104). Lanham, MD: Rowman \& Littlefield.

Solomon, R. P. (1997). Race, role modeling and representation in teacher education and teaching. Canadian Journal of Education, 22(4), 395-410.

Statistics Canada. (2017). Immigration and diversity: Population projections for Canada and its regions (91-551-X). Retrieved from http://www5.statcan.gc.ca/olc-cel/olc.action?objId=91-551X\&objType $=2 \&$ lang=en\&limit $=0$

Swanson, K. W. (2010). Delightfully difficult work: Transformation for teaching and learning. V. Wang (Ed.). Encyclopedia of information communication technologies and adult education integration (pp. 169-183). Hershey, PA: IGI Publishing.

Swanson, K. W. (2014). Research and relationships. In K. W. Swanson (Ed.), Multidisciplinary collaboration. The scholarship of teaching and learning. New directions in teaching and learning (pp. 3-10). San Francisco, CA: Jossey-Bass. 
Trofimovich, P., Isaacs, T., Kennedy, S., Saito, K., \& Crowther, D. (2016). Flawed self-assessment: Investigating self- and other perception of second language speech. Bilingualism: Language and Cognition, 19(1), 122-140. https://doi.org/10.1017/S1366728914000832

Tschannen-Moran, M., \& Woolfolk Hoy, A. (2001). Teacher efficacy: Capturing an elusive construct. Teaching and Teacher Education, 17(7), 783-805. http://dx.doi.org/10.1016/S0742051X(01)00036-1

Villegas, A. M., \& Lucas, T. (2002). Preparing culturally responsive teachers: Rethinking the curriculum. Journal of Teacher Education, 53(1), 20-32. https://doi.org/10.1177/0022487102053001003

Villegas, A., \& Lucas, T. (2004). Diversifying the teacher workforce: A retrospective and prospective analysis. In M. Smylie \& D. Miretzky (Eds.), Developing the teacher workforce (Series: Yearbook of the National Society for the Study of Education. Vol. 103; pp. 70-104). Chicago, IL: University of Chicago Press.

Walsh, S. C., Brigham, S. M., \& Wang, Y. (2011). Internationally educated female teachers in the neoliberal context: Their labour market and teacher certification experiences in Canada. Teaching and Teacher Education, 27(3), 657-665. http://dx.doi.org/10.1016/j.tate.2010.11.004

Webster, N. L., \& Valeo, A. (2011). Teacher preparedness for a changing demographic of language learners. TESL Canada Journal, 28(2), 105-128. https://doi.org/10.18806/tesl.v28i2.1075

Woolfolk Hoy, A., \& Spero R. B. (2005). Changes in teacher efficacy during the early years of teaching: A comparison of four measures. Teaching and Teacher Education, 21(4), 343-356.

Zietsma, D. (2010). Immigrants working in regulated occupations (Catalogue No. 75-001-X). Ottawa, ON: Statistics Canada. Retrieved from http://www.statcan.gc.ca/pub/75-001-x/2010102/ article/11121-eng.htm

\section{Appendix: Culturally Responsive Teaching Self-Efficacy (CRTSE) Scale:}

Please judge your capabilities to engage in the following teaching practices on a scale of 0 meaning no feelings of self-efficacy to 10 meaning high feelings of self-efficacy.

1. I adapt instruction to meet the needs of my students.

2. I obtain information about my students' academic strengths and weaknesses.

3. I determine whether my students like to work alone or in a group.

4. I identify ways that the school culture (e.g., values, norms and practices) is different from my students' home culture.

5. I implement strategies to minimize the effects of the mismatch between my students' home culture and the school culture.

6. I assess student learning using various types of assessments.

7. I obtain information about my students' home life.

8. I build a sense of trust in my students.

9. I establish positive home-school relations.

10. I use a variety of teaching methods such as visual aids.

11. I develop a community of learners when my class consists of students from diverse backgrounds.

12. I use my students' cultural background to help make learning meaningful.

13. I use my students' prior knowledge of subjects such as science to help them make sense of new information.

14. I identify ways how students communicate at home may differ from the school norms.

15. I obtain information about my students' cultural background such as their L1 (first language) or mother tongue. 
16. I teach students about their cultures' contributions to fields such as science if content and context permit.

17. I greet English Language Learners with a phrase in their native language if I am able to.

18. I design a classroom environment using displays that reflect a variety of cultures.

19. I develop a personal relationship with my students.

20. I identify ways that standardized tests such as the EQAO (Education Quality and Accountability Office) may be biased toward linguistically diverse students.

21. I communicate with parents regarding their child's educational progress.

22. I structure parent-teacher conferences so that the meeting is not intimidating for parents.

23. I help students to develop positive relationships with their classmates.

24. I revise instructional material to include a better representation of cultural groups.

25. I critically examine the curriculum to determine whether it reinforces negative cultural stereotypes.

26. I model classroom tasks to enhance English Language Learners' understanding.

27. I communicate with the parents of English Language Learners regarding their child's achievement.

28. I help students feel like important members of the classroom.

29. I identify ways that standardized tests such as the EQAO may be biased toward culturally diverse students.

30. I use a learning preference inventory to gather data about how my students like to learn (e.g., are they visual, linear, kinesthetic, or auditory learners?).

31. I use examples that are familiar to students from diverse cultural backgrounds.

32. I obtain information regarding my students' academic interests.

33. I use the interests of my students to make learning meaningful for them.

34. I implement cooperative learning activities for those students who like to work in groups.

35. I am mindful when using Canadian cultural metaphors as analogies to teach subject-specific concepts (e.g., scientific or mathematical).

36. I understand that English Language Learners' cultural beliefs regarding certain subject-specific concepts may differ from my own.

37. I give students the opportunity to improve their proficiency in English in my class.

38. I am mindful when using illustrations or metaphors from mainstream popular culture (including movies, television and music) as analogies to teach scientific or mathematical concepts.

39. I repeat content-specific terms and phrases multiple times so that English Language Learners can comprehend them better.

40. I encourage English Language Learners to use their first language (L1) to define and understand contentspecific terms and phrases. 